\title{
Design of a capillary viscometer with numerical and computational methods
}

\author{
A. Shah, D. Brabazon and L. Looney \\ School of Mechanical and Manufacturing Engineering, Materials Processing Research Centre, \\ Dublin City University, Glasnevin, Dublin 9, Ireland
}

\begin{abstract}
A high temperature and shear rate capillary viscometer has been designed, constructed and recently commissioned. This device will be used to measure the viscosity of semi-solid metals under the high temperature and shear rate conditions, similar to those found in industry. Design criteria for the device included a requirement for a highly controllable temperature $\left( \pm 1^{\circ} \mathrm{C}\right)$ up to $650^{\circ} \mathrm{C}$, capability for injection shear rates above $10,000 \mathrm{~s}-1$ and controllable injection profiles. The design of this viscometer was aided with the use of numerical modelling methods based on a power law thixotropic fluid flow relation. This analysis allowed calculation of required injection speeds and expected system forces. Computational modelling work, based on current power law fluid models, was also performed in order to investigate how the viscosity would be expected to fluctuate with shear rate and fraction solid. This data could then be used to compare with experimental work. The computational model was a 2D two-phase theoretical unsteady state model. This was used to evaluate the viscosity of semi-solid metals passing through the designed capillary viscometer at injection speeds of $0.075,0.5$ and $1 \mathrm{~m} / \mathrm{sec}$. The effects of fractions solid (fs) of the metal from $0.25,0.3,0.33$ and 0.50 were also investigated. Strong correlations between these parameters and the resulting viscosity were noted.
\end{abstract}

Keywords: semi-solid metal; viscosity; numerical and computational modelling.

\section{Introduction}

Semi-Solid metal Processing (SSP), also called Thixoforming, is relatively a new technology for the near net shaping of the engineering components. Its success depends on the achievement of a suitable microstructure prior to deformation and on the knowledge of the rheological properties of the material. The rheological data are necessary in order to describe and control the flow of the semi-solid material (Ferrante et al., 1998). One important factor affecting the rheology in SSP is that the alloy must have a solid metal spheroidal structure rather than dendritic in the liquid matrix (Kapranos et al.).

The most important application of SSP is the series production of large batches in the automotive sectors. In automobile industry, there is an increasing tendency of using lightweight and higher quality parts, because we are now confronted with the need of less fuel consumption and precaution against stringent exhaust gas regulation. SSP made a significant weight reduction in the manufacturing of automobile components such as drum disk, steering knuckle, steering arms, 
engine brackets, front and rear suspension arm, oil pump, fuel rail, wheels, pistons, body frame and motor housings. It has also been used widely in manufacturing of small components such as golf putter heads, actuator arms and luxury ergonomic pens. Due to the sounder parts produced, one of the primary advantages of SSP is improved mechanical properties when compared to conventional castings. Other advantages include lower temperature processing and the fact that the process is Near Net Shape (NNS) (

2000). Previous studies which have investigated the rheology of semi-solid materials have mainly been conducted at low shear rate (Alexandrou and Burgos, 1996; Brabazon et al., 2003; Joly and Mehrabian, 1976; Spencer et al., 1972). While these studies have provided useful information, they only provide information on the rheology behaviour up to shear rates of a few hundred per second. In the actual processing of semi-solid metals, shear rates of tens of thousands are encountered. A viscometer that will allow the investigation of flow development at these shear rates was therefore required. With knowledge of how the flow behaves at these shear rates, control strategies can be developed for SSP. This was the motivation for this work. Some other workers have produced model (Gautham and Kapur, 2005; Kumar and Dutta, 2005; Orgeas et al., 2003) and experimental (Afrath et al., 2004; Bernhard et al., 1998; Grimming, 2002; Modigell and Koke, 1999; Nohn and Hartmann, 2000; Paradies et al., 1996) results for variations on this type of viscometer. However, experimental data is still very sparse

\section{Experimental viscometer developed}

A schematic layout of the capillary viscometer developed is shown in Figure 1.

Figure 1: Capillary viscometer schematic, 1: motor, 2: injection chamber and furnace, 3: capillary and furnace, 4: load cell and 5: quench tank

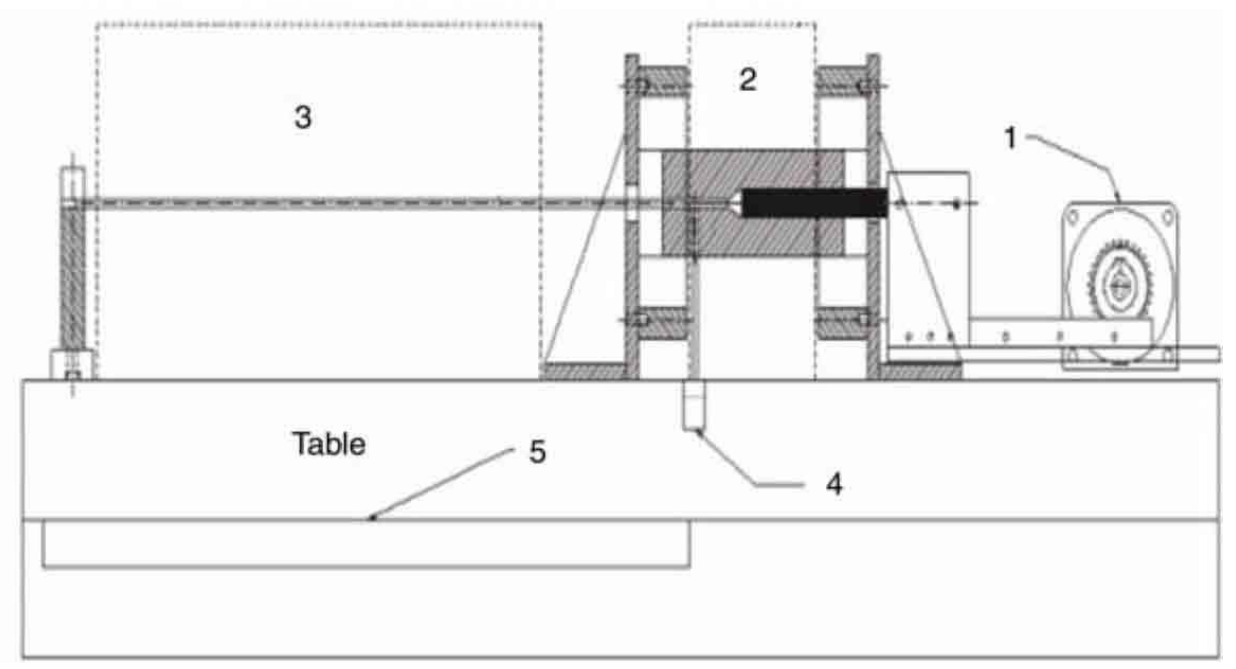


The main sections of the injection chamber (2) the capillary (3) and the plunger drive system (1) can be seen. Preliminary testing with polypropylene plastic has confirmed the effectiveness of the device to measure viscosity. The capillary viscometer is a single-point system that can be used to determine the viscosity by measuring the flow rate and pressure difference between the two ends of the capillary tube, as the viscosity is directly proportional to the pressure drop and inversely proportional to the flow rate. The theory which is based on the Hagen-Poiseulle law provides the following equation for use with this equipment

$$
\eta=\frac{\Delta P \pi R^{4}}{8 L Q}
$$

where $\Delta \mathrm{P}$ is the pressure drop along the length of the capillary in $\mathrm{Pa}, \mathrm{R}$ is the radius of the tube in $\mathrm{m}, \mathrm{L}$ is the length in $\mathrm{m}$, while $\mathrm{Q}$ is the flow rate, $\mathrm{m}^{3} / \mathrm{sec}$, through the tube. This equation applies for a fluid where the flow is laminar, there is no slip at the wall of the tube and the rate of shear depends upon the shear stress at that point. The shear rate at the wall of the capillary is given by

$$
\gamma \gamma_{w=\frac{4 Q}{\pi R_{C}^{3}}}\left(\frac{3}{4}+\frac{1}{4 n}\right)
$$

where $\mathrm{Q}_{1=} \mathrm{A}_{1} \mathrm{x} \mathrm{V}_{1}$ and $\mathrm{A}_{1=} \pi R_{c}^{2}$

where $\mathrm{Q}$ is the flow rate, $\mathrm{m}^{3} / \mathrm{sec}, \mathrm{A} 1$ is the capillary cross sectional area in $\mathrm{m}^{2}, \mathrm{~V}_{1}$ is the velocity $\mathrm{m} / \mathrm{sec}$ in the capillary tube, $R_{c}$ is the radius in $\mathrm{m}$ of the capillary tube and $\mathrm{n}$ is the flow index (dimensionless)

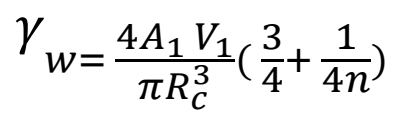

By putting different values of shear rate and flow index into this equation, different values can be calculated for velocity in the tube by applying the conservation equation

$\mathrm{A}_{1} \mathrm{~V}_{1}=\mathrm{A}_{2} \mathrm{~V}_{2}$

where A1 and A2 are area of the capillary and die-chamber, respectively. Putting values of V1, A1 and A2 in Equation (6), V2 can be found which is the velocity of semi-solid in die-chamber $\mathrm{V}_{2}=2 \pi \mathrm{R}_{2} \mathrm{~N}$ 
where $\mathrm{R} 2$ is the radius of gear and $\mathrm{N}$ is the rev/sec. The motor used in the designed experimental work had a gear ratio of 1:7. Table 1 shows different values of velocities, both linear and rotational at different values of shear rate for a typical flow index used for semi-solid metals of $n$ $=-0.1$.

Table 1 Velocity values for different shear rates with a flow index of $n=-0.1$

\begin{tabular}{lcccc}
\hline $\begin{array}{l}\text { Shear rate, } \\
\text { l/sec }\end{array}$ & $\begin{array}{l}\text { Capillary } \\
\text { velocity, } \mathrm{m} / \mathrm{sec}\end{array}$ & $\begin{array}{l}\text { Die-chamber } \\
\text { velocity, } \mathrm{m} / \mathrm{sec}\end{array}$ & $\begin{array}{l}\text { Rotational speed, } \\
\text { rev/min }\end{array}$ & $\begin{array}{l}\text { Motor speed, } \\
\text { rev/min }\end{array}$ \\
\hline 3.1 & 0.00132 & 0.000076 & 0.0584 & 0.40928 \\
6.3 & 0.0027 & 0.000155 & 0.11882 & 0.83176 \\
23.7 & 0.0101 & 0.000585 & 0.447 & 3.129 \\
54.9 & 0.02352 & 0.001355 & 1.03546 & 7.2482 \\
82.7 & 0.03544 & 0.002041 & 1.5597 & 10.9158 \\
112.8 & 0.04834 & 0.002784 & 2.1275 & 14.8925 \\
500 & 0.21428 & 0.012342 & 9.43042 & 66.0129 \\
1000 & 0.42857 & 0.02468 & 18.8608 & 132.025 \\
10,000 & 4.2857 & 0.2468 & 188.608 & 1320.26 \\
\hline
\end{tabular}

The maximum rotational speed of the motor is $3200 \mathrm{rpm}$. Therefore, it can be seen that the range of shear rates that need to be investigated can be examined with this system. In order to determine the load cell rating for the operating conditions, Equation 1 was used with the same specified shear rates (and hence flow rates, Q) and specified typical expected viscosities. Table 2 shows different values of calculated pressure difference, also for a flow index (for flow rate calculation) of

$\mathrm{n}=-0.1$.

A $250 \mathrm{~N}$ load cell with a $6 \mathrm{~mm}$ diameter loading button was used for fluid pressure measurement (at point 4 in Figure 1). This would be capable of recording $8.84 \mathrm{MPa}$ of pressure. Three readings in the bottom right of Table 1 , at high viscosity and shear rate, are above $8.84 \mathrm{MPa}$ and so could not be recorded with a $250 \mathrm{~N}$ load cell. The load cell can be seen to present an upper limit to the measurement range of the viscometer. 
Table 2 Pressure differential, $\Delta P$, values at different shear rates and viscosities of the semi-solid with flow index of $n=-0.1$

\begin{tabular}{|c|c|c|c|c|c|}
\hline $\begin{array}{l}\text { Shear } \\
\text { rate, } \\
1 / \text { sec }\end{array}$ & $\begin{array}{l}\triangle P \text { at } \\
\eta=0.01 \mathrm{~Pa} \mathrm{sec} \\
(\mathrm{Pa})\end{array}$ & $\begin{array}{l}\triangle P \text { at } \\
\eta=0.1 \text { Pa sec } \\
(\mathrm{Pa})\end{array}$ & $\begin{array}{l}\triangle P \text { at } \\
\eta=1 \text { Pa sec } \\
(P a)\end{array}$ & $\begin{array}{l}\triangle P \text { at } \\
\eta=10 \text { Pa sec } \\
(\mathrm{Pa})\end{array}$ & $\begin{array}{l}\triangle P \text { at } \\
\eta=100 \text { Pa sec } \\
(\text { Pa })\end{array}$ \\
\hline 3.1 & 4.73104 & 47.3104 & 473.104 & 4731.04 & 21,449 \\
\hline 6.3 & 9.609168 & 96.09168 & 960.91 & 9609.1 & $76,30,460$ \\
\hline 23.7 & 36.168 & 361.68 & 3616.8 & 36,168 & $1,52,61,520$ \\
\hline 54.9 & 83.724 & 837.24 & 8372.4 & $83,724.7$ & $15,26,15,200$ \\
\hline 82.7 & 126.208 & 1262.08 & $12,620.8$ & $1,26,208$ & \\
\hline 112.8 & 172.144 & 1721.44 & $17,214.4$ & $1,72,144$ & \\
\hline 500 & 763.046 & 7630.46 & $76,304.6$ & $7,63,046$ & \\
\hline 1000 & 1526.152 & $15,261.52$ & $1,52,615.2$ & $15,26,152$ & \\
\hline 10,000 & $15,261.52$ & $1,52,615.2$ & $15,26,152$ & $1,52,61,520$ & \\
\hline
\end{tabular}

\section{Computational simulations}

An Eulerian multiphase model, based on current non-Newtonian power law fluid models present above, was used in this work. Assumptions in this modelling work included that the flow was laminar, axisymmetric, isothermal and incompressible. Slip at the boundary wall was also assumed. Material property data for aluminium alloy A356 was used for these simulations and kept constant for all simulations. The thixotropic behaviour of semi-solid aluminium was studied through simulations with different input velocity boundary conditions. In Fluent, three sets of simulation results were performed with inlet velocities of $0.075 \mathrm{~ms}-1,0.5 \mathrm{~ms}-1$ and $1 \mathrm{~ms}-1$ and at different solid fractions, $0.25,0.30,0.33$ and 0.5 . The dimensions of the model grid were those of the cavity in the actual experimental rig, shown in Figure 1. The grid represents the $125 \mathrm{~mm}$ long and $25 \mathrm{~mm}$ in diameter injection chamber, the conical face 30o angled inlet to the capillary, and the $740 \mathrm{~mm}$ long and $6 \mathrm{~mm}$ diameter capillary section. The purpose of the simulations was to obtain transient response flow data during SSP. During the simulation, dynamic pressure, velocity and viscosities were continuously recorded at each point along the grid sections so that they could be assessed with the different plunger velocity and solid fraction set conditions. Transient flow results were recorded at a time interval of $2 \mathrm{sec}$ for inlet velocity of $0.075 \mathrm{~m} / \mathrm{sec}$, $0.28 \mathrm{sec}$ for an inlet plunger speed of $0.5 \mathrm{~m} / \mathrm{sec}$ and $0.1 \mathrm{sec}$ for an inlet plunger velocity of 1 $\mathrm{m} / \mathrm{sec}$. Transient results are more important in this process than steady state as actual processing occurs in a very short time period. The results from computational work for the viscosity variation along the chamber and capillary, of $0.25 \mathrm{fs}$ A356 at the various injection speeds, are shown in Figure 2. 
Figure 2 Transient state viscosity of A356 at $0.25 s f$

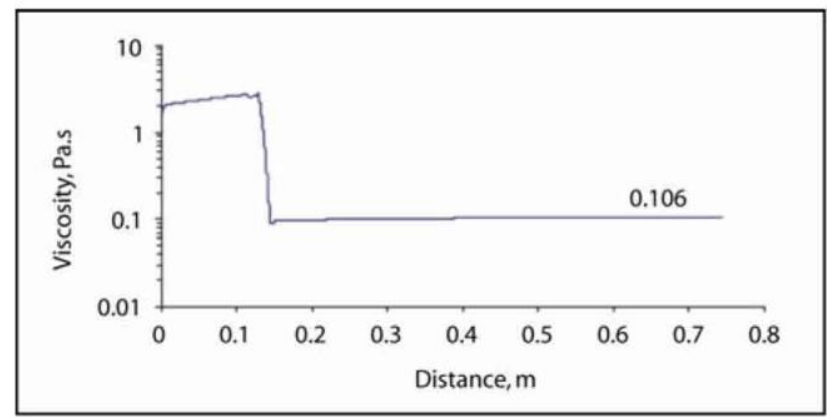

(a)

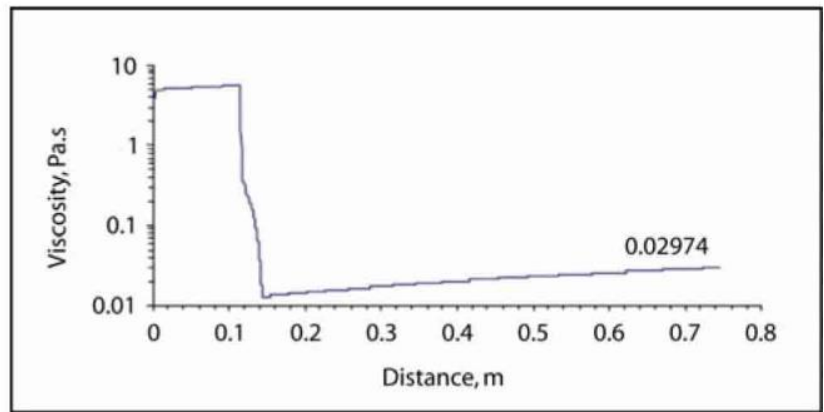

(b)

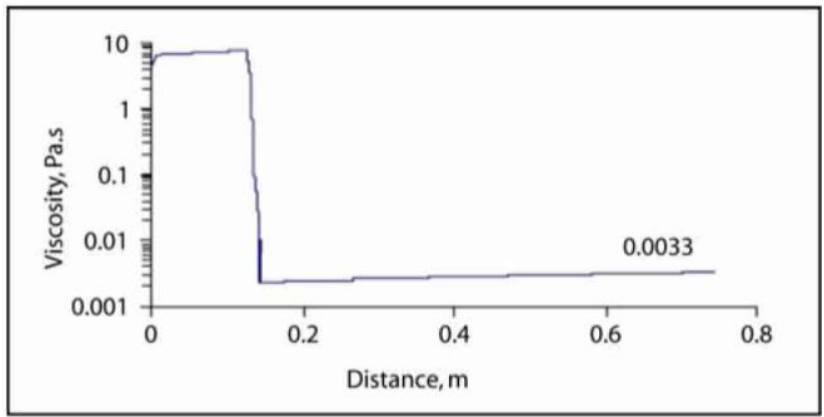

(c)

\section{Conclusions}

There has been much debate as to the rheological evolution of semi-solid metals at high shear rate. At similar high shear rates to those found in industry, some studies indicate a proportional increasing viscosity for increasing shear rate. Experimental data at these higher shear rates are still lacking to devise an appropriate model to describe this regime. Numerical methods were used in this work to aid the design of a new capillary viscometer, which it is hoped will provide this required experimental data. Computational work has also been performed which has not only allowed validation with previous experimental low shear rate viscosity data but also provides the opportunity to assess the validity of current models at higher shear rates 


\section{References}

Afrath, C., Aguilar, J. and Buehrig-polaczek, A. (2004) 'Rheological measurement of semi-solid alloys under high shear rate conditions', 8th International Conference on Semi-Solid Metal Processing of Alloys and Composites.

Alexandrou, A. and Burgos, G.R. (1996) 'Mathematical and computational modelling in diefilling in semi-solid metal processing', Journal of Material Processing Technology, pp.59-72.

Apelian, D. (2000) 'A roadmap for semi solid processing', 6th International Conference on Semi Solid Processing of Alloys and Composites, pp.47-54.

Bernhard, D., Spath, H.M. and Sahm, P.R. (1998) 'Investigation of rheology of semi-solid materials by using a modified capillary viscometer and numerical simulation', 5th International Conference on Semi Solid Processing of Alloys and Composites, pp.51-55.

Brabazon, D., Browne, D.J. and Carr, A.J. (2003) 'Experimental investigation of the transient and steady state rheological behaviour of Al-Si alloys in the mushy state', Material Science and Engineering, Vol. A356, pp.69-80.

Ferrante, M., de Freitas, E., Bonilha, M. and Sinka, V. (1998) 'Rheological properties and microstructure evolution of semi solid aluminium alloys inoculated with Mischmetal and Titanium', 5th International Conference on Semi Solid Processing of Alloy and Composites, pp.35-42.

Gautham, B.P. and Kapur, P.C. (2005) 'Rheological model for short duration response of semisolid metals', Material Science and Engineering, Vol. A393, pp.223-228.

Grimming, T. (2002) 'Rheological measurements of semi-solid alloys with a horizontal high temperature capillary rheometer', 7th International Conference on Semi-Solid Processing of Alloys and Composites, pp.783-786.

Joly, P.A. and Mehrabian, R. (1976) 'The rheology of a partially solid alloy', Journal of Material Science, Vol. 11, pp.1393-1418.

Kapranos, P., Ward, P.J., Atkinson, H.V. and Kirkwood, D.H. 'Near net shaping by semi solid metal processing', Material and Design, Vol. 21, No. 4, pp.387-394.

Kumar, A. and Dutta, P. (2005) 'Modelling of transport phenomenon in continuous casting of nondendritic billets', International Journal of Heat and Mass Transfer, Vol. 48, pp.3474-3488.

Modigell, M. and Koke, J. (1999) 'Rheological modelling on semi-solid metal alloy and simulation of thixocasting process', Material Processing Technology, Vol. 111, pp.53-58.

Nohn, B. and Hartmann, D. (2000) 'Use of simulation tools for optimization of the thixoforming process', 6th International Conference on Semi-Solid Metal Processing of Alloys and Composites, pp.795-800. 
Orgeas, L., Paradies, C.J., Rappaz, M., Imwinkelried, T. and Gabathuler, J.P. (2003) 'Modelling of semi-solid process using a modified temperature-dependent power-law model', Modelling and Simulation in Materials Science and Engineering, Vol. 11, pp.553-574.

Paradies, C.J., Rappaz, M., Imwinkelried, T. and Gabthuler, J.P. (1996) 'Simulation of the pressure die casting of a thixotropic aluminium alloy', 4th International Conference on SemiSolid Processing of Alloy and Composites, pp.115-119.

Spencer, D.B., Flemings, M.C. and Mehrabian, R. (1972) 'Rheological behaviour of Sn-15\%Pb in the crystallization range', Metallurgical Transactions, Vol. 3, pp.1925-1932 